\title{
O DESENVOLVIMENTO HISTÓRICO-CULTURAL DA IMAGINAÇÃO NA ADOLESCÊNCIA E A EDUCAÇÃO ESCOLAR
}

\author{
EL DESARROLLO HISTÓRICO-CULTURAL DE LA IMAGINACIÓN EN LA \\ ADOLESCENCIA Y LA EDUCACIÓN ESCOLAR
}

\author{
THE HISTORICAL-CULTURAL DEVELOPMENT OF IMAGINATION IN \\ ADOLESCENCE AND THE SCHOOL EDUCATION
}

Ricardo Eleutério dos ANJOS ${ }^{1}$

\begin{abstract}
RESUMO: O presente artigo versa sobre a relação entre educação escolar e desenvolvimento da imaginação na adolescência. A partir dos pressupostos da psicologia histórico-cultural, defende que a imaginação não se desenvolve naturalmente, tampouco se desenvolve fora das atividades que a requeira. Os produtos da imaginação começam a se expressar, em suas máximas possibilidades, a partir da adolescência, por meio do pensamento por conceitos que, outra coisa não é, senão, a forma mais desenvolvida de pensamento que, de acordo com Vigotski (2014), é engendrada no processo de transmissão-assimilação dos conteúdos escolares.
\end{abstract}

PALAVRAS-CHAVE: Imaginação. Adolescência. Educação escolar.

RESUMEN:El presente artículo versa sobre la relación entre educación escolar y desarrollo de la imaginación en la adolescencia. A partir de los presupuestos de la psicología histórico-cultural, defiende que la imaginación no se desarrolla naturalmente, tampoco se desarrolla fuera de las actividades que la requiera. Los productos de la imaginación empiezan a expresarse, en sus máximas posibilidades, a partir de la adolescencia, por medio del pensamiento por conceptos que, otra cosa no es, sino la forma más desarrollada de pensamiento que, de acuerdo con Vigotski (2014), es engendrada en el " proceso de transmisión-asimilación de los contenidos escolares.

PALABRAS CLAVE: Imaginación. Adolescencia. Educación escolar.

ABSTRACT: This article is about the relationship between school education and the development of imagination in adolescence. Through the suppositions of HistoricalCultural psychology, defends that the imagination doesn't develop by itself, neither out of the activities that requires it. The results of imagination begin to express themselves, in its maximum possibilities, in adolescence, through the thought by concepts, the most developed form of thought, that according to Vigotski, it's generated through the process of streaming-assimilation of the school contents.

${ }^{1}$ Universidade Estadual Paulista (Unesp), Araraquara - SP - Brasil. Doutorando pelo programa de PósGraduação em Educação Escolar. E-mail: ricardo.eleuterio@ hotmail.com 
KEYWORDS: Imagination. Adolescence. School education.

\section{Introdução}

O estudo do desenvolvimento psíquico na adolescência (ou em qualquer outra época do desenvolvimento humano), não deve se limitar à descrição, mas sim à análise e explicação da formação dinâmica de tal desenvolvimento. A nova estrutura da personalidade do adolescente, tão distinta da personalidade infantil, é analisada por Vygotski (1996, 225, grifos meus) a partir de vários estágios, “[...] passando das atrações aos interesses, dos interesses às funções psíquicas e destas ao conteúdo do pensamento e à imaginação criativa".

Para Vygotski, a conversão da atração (base biológica, instintiva) em interesses é a chave para se compreender o desenvolvimento psíquico do adolescente. $O$ desenvolvimento dos interesses constitui o conteúdo do desenvolvimento social e histórico, também denominados de necessidades superiores. Por meio do trabalho (atividade vital humana), o ser humano modifica a natureza para suprir suas próprias necessidades e, a cada necessidade suprida, surgem novas necessidades mais complexas, que exigem do ser humano um psiquismo mais complexo e sofisticado. Nesse processo, as necessidades naturais sofrem uma profunda mudança devido ao contexto histórico-cultural, a "[...] necessidade do homem se converte em necessidade humana". (VYGOTSKI, 1996, p. 21).

Os velhos interesses da infância vão desaparecendo e surgem novos interesses que se configuram como força motriz das funções psíquicas, da conduta humana. Para Vigotski (2014) o processo de extinção dos velhos interesses e o desenvolvimento dos novos é, particularmente, um processo longo, sensível e doloroso. Para o autor, existem períodos de crise no desenvolvimento humano e a perda dos interesses que antes orientavam a atividade do indivíduo provoca a necessidade de uma viragem. Porém, por trás de cada crise se oculta um conteúdo positivo, caracterizado num salto qualitativo a uma nova e superior forma de vida. No caso da adolescência, as crises enfrentadas marcam o surgimento de uma nova forma de pensar, qual seja: o pensamento por conceitos, que é base para a estruturação da personalidade e da concepção de mundo.

Devido ao pensamento por conceitos, todas as demais funções psicológicas se intelectualizam, possibilitando o salto qualitativo das funções espontâneas às voluntárias e o consequente desenvolvimento da autoconsciência e do autodomínio da 
conduta. Além disso, o pensamento por conceitos possibilita a liberdade e a intencionalidade da ação, premissas indispensáveis ao desenvolvimento da imaginação criativa. A imaginação criativa, por sua vez, como assinala Davidov (1988, p. 97), é a essência da personalidade do ser humano, pois está ligada às suas possibilidades criadoras, ou seja, sua capacidade de criar novas formas de vida social. De acordo com o autor, "o nível da personalidade, na organização psicológica do indivíduo, é o procedimento para dominar o próprio futuro com a ajuda das ações criadoras".

É neste contexto que o presente artigo propõe aportes teóricos à educação escolar, a partir dos pressupostos da psicologia histórico-cultural, notadamente por meio da análise da relação entre educação escolar e o desenvolvimento da imaginação na adolescência. Para tanto, foi dividido em dois itens: o primeiro refere-se à concepção de imaginação à luz da psicologia histórico-cultural; o segundo, à imaginação e seu desenvolvimento na adolescência.

\section{A concepção de imaginação à luz da psicologia histórico-cultural}

De acordo com a psicologia histórico-cultural, o psiquismo humano é entendido como a imagem subjetiva da realidade objetiva. Essa representação mental da realidade é formada no cérebro por meio de um sistema funcional complexo, constituído de funções psíquicas afetivo-cognitivas tais como sensação, percepção, atenção, memória, pensamento, linguagem, imaginação, emoção e sentimento (MARTINS, 2013).

A atividade vital humana, o trabalho, é uma atividade mediada por instrumentos de trabalho e pela linguagem. Tal mediação cultural confere atributo consciente ao psiquismo humano, o que torna o indivíduo capaz de antecipar mentalmente o produto de suas ações. Dessa forma, o psiquismo não se apresenta apenas como reflexo subjetivo da realidade, mas também como uma capacidade do ser humano criar novas imagens, novas representações mentais da realidade. Essa é a singularidade da imaginação que, de acordo com Ignatiev (1960, p. 308), trata-se da "[...] criação de imagens com forma nova, é a representação de ideias que depois se transformam em coisas materiais ou em atos práticos do homem".

As novas imagens, ou representações mentais, orientam o ser humano na atividade teleológica, com vistas, inclusive, à mudança da própria realidade, pois, para transformar a realidade objetiva faz-se necessário saber mudá-la mentalmente, “[...] essa exigência é cumprida pela imaginação". (RUBINSTEIN, 1973, p. 97). Não obstante a 
isso, a imaginação não prescinde da atividade humana, pelo contrário, a imaginação é produto ou resultado do desenvolvimento da atividade criadora e, a partir dos vínculos daí estabelecidos, a imaginação torna-se, também, condição para a atividade consciente.

Se o homem se visse privado por completo da capacidade de sonhar, se de vez em quando não pudesse adiantar-se a ver, através da sua imaginação, em toda a sua perfeita beleza, a obra que justamente se está formando sob as suas mãos, decididamente eu não poderia imaginar que razão pudesse induzir o homem a empreender e levar a cabo os grandiosos e esgotantes trabalhos no campo da arte, da ciência e da prática. (LENINE , 1949, p. 352 apud RUBINSTEIN, 1973, p. 106).

Os vínculos que se estabelecem entre atividade e imaginação remete-nos a discussão sobre dois tipos de imaginação, quais sejam: a imaginação passiva e a ativa. A imaginação passiva é aquela cujas representações não são acompanhadas de ações e que, por vezes, se apresentam como substitutas das ações. Trata-se de uma fuga do real, de meros sonhos "[...] com os quais muita gente se escusa pondo assim uma cortina entre o mundo real e a necessidade de modificá-lo". (RUBINSTEIN, 1973, p. 106). Nesses casos, o indivíduo se mostra como um hóspede temporário da realidade, pois está envolvido demais em suas fantasias sem, no entanto, motivos para a ação. A imaginação ativa, pelo contrário, apresenta-se como força motriz à ação, caracterizada por seus atributos reprodutivos e criativos.

Em seus atributos reprodutivos, a imaginação está diretamente ligada à memória, por se tratar da reprodução de imagens relacionadas às experiências do anteriormente percepcionado. Saccomani (2016, p. 70) assevera que, “[...] quando mencionamos a memória, não estamos referindo-nos tão somente à memória do indivíduo singular, mas à memória do gênero humano". Nesse ponto a autora ressalta o importante papel da educação escolar no desenvolvimento da imaginação que, ao transmitir os conteúdos sistematizados, contribui para o enriquecimento da memória do aluno.

De acordo com Vigotski (2014, p. 1), a essência do atributo reprodutivo da imaginação "[...] consiste no fato de o homem reproduzir ou repetir normas de comportamento anteriormente criadas e elaboradas, ou relembrar impressões passadas". Porém, o autor salienta que o cérebro humano não se limita a reprodução de imagens de experiências passadas, mas também cria novas imagens a partir de tais experiências, esse é o atributo criativo da imaginação. 
Se a atividade do homem se reduzisse apenas à repetição do passado, então o homem seria um ser voltado somente para o passado e incapaz de se adaptar ao futuro. É justamente a atividade criadora humana que faz do homem um ser que se projeta para o futuro, um ser que cria e modifica o seu presente. (Idem, p. 3).

Assim, enquanto que a reprodução é característica da memória, a transformação do reproduzido é característica fundamental da imaginação. No entanto, devemos observar que há uma relação entre imaginação e memória, posto que a imaginação baseia-se na experiência, enquanto que a memória, dificilmente reproduzirá, de forma fiel, o experienciado, sua reprodução conterá inexatidões, deformações e modificações involuntárias.

A imaginação se separará da reprodução, bem como do imediatamente percebido, tão somente quando essa independência se mostrar consciente. A imaginação, no sentido restrito da palavra, é caracterizada a partir do momento em que o desenvolvimento das imagens deixa de ser uma modificação involuntária e, de certa forma, uma deformação das ideias imaginativas. A imaginação vai diferindo-se da memória à medida que se desenvolve a níveis mais superiores, portanto, voluntários.

A imaginação significa uma separação da experiência passada, uma transformação do dado e, nesta base, a reprodução de novas imagens, que são simultaneamente produto da atividade criadora do homem e exemplo dessa atividade. "[...] a função da memória consiste em conservar o mais fielmente possível os resultados da experiência; e a da imaginação, em transformá-la”. (RUBINSTEIN, 1973, p. 98).

Mas a imaginação não se vincula apenas à memória, pois, em suas formas mais desenvolvidas, estabelece estreita relação com a linguagem e o pensamento, o que nos remete a sua peculiaridade na qual se apresenta a partir da adolescência, por meio da formação do pensamento por conceitos. Esse é o objeto de análise a seguir.

\section{A imaginação e seu desenvolvimento na adolescência}

[...] os verdadeiros produtos da imaginação começam a se expressar na idade de transição, quando os pseudoconceitos formulados pelo adolescente vão cedendo lugar aos conceitos, nos quais radica o pensamento abstrato como forma mais complexa de representação da realidade. (MARTINS, 2013, p. 239). 
A imaginação, em sua forma mais desenvolvida exige como fator principal e indispensável, a liberdade e intencionalidade do pensamento e da ação. Tal processo só pode ocorrer mediante ao pensamento por conceitos. Nesse caso, a imaginação libertase paulatinamente das representações puramente concretas e começa a operar com elementos do pensamento abstrato, isso porque o conceito não é uma união de imagens, mas sim de juízos e de um sistema de conceitos.

A imaginação do adolescente pode se apresentar mais desenvolvida comparada com a da criança, pois, “[...] a aparente abundância das fantasias infantis é na realidade, na sua maioria, mais a expressão da debilidade do seu pensamento crítico que a da força da sua imaginação". (RUBINSTEIN, 1973, p. 119). A imaginação da criança é menos desenvolvida porque consiste principalmente no fato da criança não conhecer as leis da realidade objetiva e, por isso, facilmente viola a realidade. A imaginação do adolescente, ao substituir o jogo infantil, possibilita o rompimento da antiga relação da criança com os objetos da realidade. A formação de conceitos possibilita o adolescente sair de sua situação sensorial concreta e, a partir das abstrações daí decorrentes, elaborar e modificar a realidade. Porém, não se pode perder de vista que tal processo não ocorre natural e imediatamente, tampouco isento de uma atividade que engendre o pensamento conceitual, como a atividade de estudo (VYGOTSKI, 2001). Trata-se, portanto, de um processo de formação que vai deixando suas bases concretas à abstração e, logo em seguida, se configura em ações concretas de transformação objetiva. Observemos tal pressuposto mais de perto:

"A fantasia do adolescente é mais criativa comparada com a da criança, mas não é produtiva se a compararmos com a fantasia [imaginação] do adulto”. (VYGOTSKI, 1996, p. 218). De acordo com Rubinstein (1973, p. 121), enquanto que a imaginação do adolescente, “[...] difere do jogo infantil, de forma a poder prescindir dos objetos imediatamente concretos e palpáveis, a imaginação desenvolvida [do adulto] difere da fantasia juvenil por se moldar nos produtos objetivos palpáveis".

As asserções supracitadas só podem ser compreendidas a partir de uma concepção materialista histórico-dialética. Marx (1978, p. 116-123) em O método da economia política, ao analisar o método científico de conhecimento, afirma que o pensamento parte da representação caótica do todo para chegar às abstrações. Em seguida, faz o caminho inverso, ou seja, ascende das abstrações mais simples à complexidade do conjunto que foi representado, inicialmente, de forma caótica. $\mathrm{O}$ pensamento afasta-se momentaneamente do concreto (captado pelo pensamento, 
inicialmente, como um todo caótico) por meio das abstrações para, em última instância, voltar ao concreto, porém, agora, representando suas múltiplas determinações (concreto pensado), ou seja, o reflexo subjetivo da realidade, no cérebro humano, avança na direção de um progressivo aprofundamento da explicitação racional do movimento da realidade. Para Marx, o concreto só pode ser captado pelo pensamento científico como ponto de chegada e não de partida. Ou seja, só pode ser captado adequadamente como síntese:

O concreto é concreto porque é a síntese de muitas determinações, isto é, unidade do diverso. Por isso o concreto aparece no pensamento como o processo da síntese, como resultado, não como ponto de partida, ainda que seja o ponto de partida efetivo e, portanto, o ponto de partida também da intuição e da representação. (MARX, 1978, p. 116).

O concreto no pensamento é o conhecimento mais profundo dos fenômenos da realidade, já que seu conteúdo não é o imediatamente observável, mas sim a síntese de múltiplas determinações que só é possível a partir das abstrações.

A análise crítica da dinâmica do capital que Marx desenvolve em suas várias obras é um modelo do movimento do pensamento científico, que atinge o concreto por meio das abstrações. Mas esse método de elevação do abstrato ao concreto não se aplica apenas à análise da reprodução social regida pela lógica do capital. Trata-se de um método necessário às ciências de maneira geral. $\mathrm{O}$ passo, no pensamento, do concreto em sua forma caótica ao concreto pensado, por meio das abstrações, constitui, segundo Kopnin (1966), a lei universal do desenvolvimento dos conhecimentos humanos e ocupa um lugar especial na dialética materialista. Nas palavras do autor:

Esta lei nos permite demonstrar as leis que regem o desenvolvimento
da imagem cognoscitiva, sua dinâmica do simples ao complexo, do
inferior ao superior, o processo de formação das categorias. Sobre esta
lei se edifica a teoria das formas de pensar e sua subordinação no
processo de obtenção do verdadeiro conhecimento. Por ele, esta lei
constitui o princípio básico da lógica dialética, ao que estão sujeitas,
em última instância, todas as demais leis que regulam a dinâmica do
pensamento. Graças à argumentação materialista deste principio se
supera o enfoque metafísico, puramente empírico do pensamento e se
esclarece seu papel no conhecimento. (KOPNIN, 1966, p. 157).

Da mesma forma, a imaginação, de acordo com Vygotski (1996, p. 220), é uma atividade transformadora e criadora que parte do concreto dado (concreto caótico) ao 
concreto criado (concreto no pensamento), "ao concreto novo". O movimento do concreto dado ao concreto novo se alcança a partir das abstrações e o "[...] distanciamento do concreto, através do abstrato, para a estruturação da nova imagem concreta, é o caminho que descreve a imaginação na idade de transição [na adolescência]".

A abstração, portanto, é elemento imprescindível à criação imaginativa, mas não é o suficiente, a novidade nesse processo, segundo Vigotski (2014), é a nova imagem concreta que surge como resultado da atividade imaginativa. Mas o adolescente, por estar ainda no processo de formação do pensamento conceitual (isto se as condições materiais de educação assim o possibilitar), pode sucumbir e se enredar em fantasias improdutivas, o que configuraria uma imaginação passiva. A imaginação do adulto que se apropriou das formas mais desenvolvidas de produções materiais e ideativas do gênero humano, deve passar das formas subjetivas da fantasia às formas objetivas da imaginação criadora, que é materializada nos produtos objetivos ou nas novas formas de comportamentos especificamente humanos criadas. De acordo com Rubinstein (1973, p. 125-126):

É fundamental que a imaginação seja incorporada à atividade objetiva e não degenere numa fantasia infecunda, afastando-se assim da atividade, ocultando de certo modo a realidade com um véu. Deve-se cultivar a aptidão para "ultrapassar a realidade", recriando-a, obrigando-a deste modo a entrar mais profundamente na realidade.

Podemos, então, inferir que a atividade imaginativa tem como ponto de partida a realidade concreta e, por meio das abstrações, distancia-se de tal realidade a fim de conhecê-la em suas múltiplas determinações. A antecipação mental do produto da atividade, portanto, faz parte de um processo que tem, como ponto de chegada, a criação do novo, a criação de uma nova realidade interna e externa (imaginação ativa).

Outro aspecto que podemos elucidar sobre esse processo funcional, é a imaginação artística, onde um ideal prévio se expressa de forma concreta e plástica.

Enquanto que na ciência e na filosofia se faz necessário um "detóur para conhecer as coisas e a sua estrutura" (KOSIK, 2011, p. 27), um afastamento em relação à aparência do fenômeno, no objetivo de analisar suas múltiplas determinações, a arte mostra a aparência do fenômeno de outra forma, numa fusão com a essência, revelando ao sujeito a realidade constituída por suas contradições intensificadas, com a acentuação de sua dramaticidade (DUARTE, 2016). 
A arte trabalha com imagens da realidade, entendendo aqui - tal como já foi salientado neste artigo - o termo imagem num sentido amplo, uma representação mental, ou seja, não limitado ao sentido da visão. Outro ponto importante que deve ser ressaltado é que a relação do indivíduo receptor com essas imagens artísticas da realidade é imediata. Porém, não se trata de uma relação imediata como ocorre na vida cotidiana, pois a imediatez da vida cotidiana se resume no pragmatismo e satisfação imediata de necessidades. Na arte, a relação imediata é uma prática suspensa, as necessidades imediatas ficam em segundo plano e prevalece à entrega ao mundo da arte (DUARTE, 2016).

O papel educativo da arte, portanto, é provocar um salto qualitativo do em-si ao para-si, o salto da experiência cotidiana à experiência não cotidiana, seja ele no artista seja no receptor da obra de arte. Deixando claro que tal papel também é especificidade da ciência e da filosofia, porém, como demonstrado, por caminhos distintos. O indivíduo, por meio da obra de arte, pode reviver tramas humanas vividas num tempo e espaço muito distantes, como se fossem parte de sua própria história. Pode produzir no sujeito receptor emoções mais fortes do que experimenta na maior parte de sua vida cotidiana. A arte, portanto, liga o percurso da vida individual ao percurso histórico da humanidade (DUARTE, 2016).

O papel da arte é produzir nas pessoas um efeito que as distancie de sua cotidianidade, que possibilite o indivíduo experimentar algo que está além de suas experiências diárias. Vigotski (1999) enfatiza tal assunto ao fazer uma comparação entre duas histórias bíblicas. A primeira história é a do milagre da multiplicação dos pães e peixes. O autor utiliza esse exemplo para argumentar que o papel da arte não deveria se limitar a contagiar os indivíduos receptores com os sentimentos do artista. Também a arte não deveria ser reduzida à produção daquilo que é comum na vida das pessoas. $\mathrm{O}$ primeiro conto bíblico é uma expressão de algo quantitativo: mil pessoas que se alimentaram e se saciaram com pães e peixes, ou seja, se alimentaram com o mesmo alimento que cada uma delas comia em sua vida diária. O outro milagre bíblico lembrado pelo autor é o da transformação da água em vinho. A maravilha da arte deve ser comparada a este último milagre. A arte deve promover transformação, deve promover superação do sentimento comum e das experiências da vida cotidiana. "A arte está para a vida como o vinho para a uva [...] a arte recolhe da vida o seu material, mas produz acima desse material algo que ainda não está nas propriedades desse material" (VIGOTSKI, 1999, p. 307-308). 
A arte, como objetivação genérica para-si, ou seja, uma produção humana não cotidiana promove transformação na conduta do indivíduo, promove um salto qualitativo dos conceitos cotidianos aos conceitos científicos, processo indispensável para o desenvolvimento da imaginação criativa e à superação do imediatismo pragmático tão evidente na vida cotidiana (DUARTE, 2016).

A imaginação artística, portanto, não é caracterizada por criar, necessariamente, uma nova situação imaginada que se contraponha às exigências fundamentais da realidade da vida, mas sim, por materializá-las.

É completamente errada a opinião de que uma obra de arte manifesta tanto mais imaginação quanto mais estranha e extravagante seja:

[...] quanto mais realista for uma obra de arte, quanto mais estritamente levar em conta a realidade da vida, tanto mais poderosa deve ser a imaginação, para que o contexto intuitivo-imaginativo com que opera o artista se manifeste plasticamente na sua intenção artística. (RUBINSTEIN, 1973, p. 107-108).

Não se pode confundir a fidelidade da imaginação artística com uma reprodução fotográfica ou uma cópia do percebido. Na verdade, a finalidade da obra de arte é mostrar aos indivíduos o que o artista vê na realidade e, a partir dessa plasticidade, que também possam compreender tal realidade. De acordo com o autor supracitado, "[...] a imaginação da obra de arte permite também, naturalmente, 'ultrapassar a realidade' [...] Muitos das subtis e delicadas vivências - fatos significativos da vida interna - são sobrepostas e ocultadas pelas circunstâncias da vida cotidiana". (Idem, p. 109). Daí que a imaginação do artista esboça um quadro da realidade que se afasta do cotidiano, caracterizando-se como uma objetivação genérica para-si. O papel da arte é produzir nas pessoas um efeito que as distancie de sua cotidianidade, ou seja, que possibilite o indivíduo experimentar algo que está além de suas experiências imediatas e pragmáticas.

Ao defendermos que a apropriação dos conteúdos artísticos produzidos pelo gênero humano no percurso histórico-cultural contribuem para a superação (por incorporação) dos conceitos cotidianos aos conceitos científicos, e para o desenvolvimento das funções psicológicas superiores em suas máximas possibilidades, estamos aqui considerando que a qualidade da mediação determina a qualidade do desenvolvimento psíquico. Daí radica o importante papel da educação escolar na transmissão-assimilação dos conteúdos clássicos, sistematizados (SAVIANI, 2011). 
Não se pode perder de vista que, por meio do pensamento por conceitos, o vínculo da imaginação não se resume apenas à memória, ao pensamento e a linguagem, mas sim, a todo o sistema funcional. No caso de seu vínculo com as emoções e sentimentos, Vygotski (1996, p. 221-222) assevera que a imaginação do adolescente, mesmo por vezes assentados nas fantasias irreais, engendra sentimentos e emoções reais por meio dos quais sua conduta é motivada.

Além disso, segundo o autor, a imaginação do adolescente é um meio pelo qual ele pode orientar sua vida emocional e dominá-la. Assim como um adulto que, ao perceber uma obra de arte, supera seus próprios sentimentos, o adolescente, em suas fantasias, se reconhece e se compreende. $\mathrm{O}$ adolescente representa em imagens criativas suas emoções, “[...] o vivido encontra sua expressão em imagens criativas. [...] as imagens criativas formadas pela imaginação do adolescente, cumpre para ele a mesma função que cumpre a obra artística em relação ao adulto." (VYGOTSKI, 1996, p. 222).

A imaginação em suas formas mais desenvolvidas, diante de todos seus atributos e características, apresenta-se sempre a partir da realidade objetiva, e quanto maior for o conhecimento do indivíduo sobre a realidade, maior será a expressão de sua imaginação.

É condição indispensável para o desenvolvimento de uma sã e eficaz imaginação que se ampliem e enriqueçam as experiências do estudante. Só assim a sua imaginação será frutuosa. É importante darlhe a conhecer novas fontes da realidade objetiva à qual não está habituado, dada a sua limitada experiência cotidiana. (RUBINSTEIN, 1973, p. 125).

A partir do exposto acima, destacamos o papel da educação escolar de adolescentes que, em sua especificidade, possibilita a formação do pensamento por conceitos, a liberdade das ações e o desenvolvimento da imaginação em suas máximas possibilidades. O produto da atividade imaginativa será tão rico quanto for $\mathrm{o}$ conhecimento que o indivíduo tenha sobre o conteúdo imaginado. Não se pode esperar do adolescente uma obra criativa se este não tiver acesso aos conhecimentos específicos sobre o que se deseja criar. Tais conhecimentos servirão de mediações à atividade criativa.

Portanto, uma educação escolar que reduza seu conteúdo ao cotidiano do aluno não pode esperar deste, a criação de imagens e representações para além do que conhece. Nesse caso, o conteúdo imaginativo do adolescente se apresentará sempre 
aquém do que poderia alcançar se tivesse acesso aos conteúdos clássicos, não cotidianos.

Quando alcança o domínio do conteúdo sistematizado, o adolescente torna-se livre em sua criação. No entanto, para que isso seja possível, faz-se necessário um longo processo, "às vezes ingente", de repetições e automatizações das atividades, pois o automatismo é condição de liberdade e "não é possível ser criativo sem dominar determinados mecanismos". (SAVIANI, 2011, p. 17, grifos meus).

Tal processo é válido tanto para o manejo dos instrumentos técnicos, quanto para o dos instrumentos psicológicos, os signos.

A principal característica do processo de apropriação ou de 'aquisição' que descrevemos é, portanto, criar no homem aptidões novas, funções novas. É nisso que se diferencia do processo de aprendizagem dos animais. Enquanto este último é resultado de uma adaptação individual do comportamento genérico a condições de existência complexas e mutantes, a assimilação no homem é um processo de reprodução, nas propriedades do indivíduo, das propriedades e aptidões historicamente formadas da espécie humana. (LEONTIEV, 1978, p. 270, grifos meus).

Portanto, ao apropriar-se dos conteúdos sistematizados, o ser humano pode objetivar-se neles, o que quer dizer que as mesmas capacidades outrora desenvolvidas no gênero humano, tais como o ouvido musical, a contemplação artística, o pensamento abstrato, ou seja, a humanização dos sentidos (MARX, 2015), podem ser engendradas no indivíduo singular. Eis aí, a função humanizadora da educação escolar.

Tal como nos demais processos funcionais, as necessidades superiores, sociais, também são forças motrizes da imaginação. Para Vygotski (1996, p. 221), “[ [...] o desejo não satisfeito é o estímulo que incentiva a imaginação. Em nossas imaginações se cumpre os desejos, se corrige a insatisfatória realidade”. Nesse contexto, o adolescente pode, simplesmente, fugir da realidade e buscar em suas fantasias a satisfação de suas necessidades, numa atitude passiva, ou pode, pelo contrário, (dada suas condições objetivas de vida) antecipar mentalmente, projetar as possibilidades de mudanças da própria realidade e buscar sua concretização.

\section{Considerações finais}

Se a educação escolar eximir a transmissão das objetivações genéricas para-si, como a ciência a arte e a filosofia, a representação imaginativa que orientará a conduta 
do adolescente às necessárias mudanças da realidade não passará de uma criação cotidiana e espontânea, portanto, reduzida aos limites das próprias experiências das esferas em-si da genericidade humana. Por outro lado, a transmissão-assimilação das objetivações genéricas para-si instrumentaliza o adolescente para que este compreenda sua vida cotidiana para além de sua aparência fetichista, possibilitando a modificação da própria cotidianidade. Deve-se, portanto, ensinar o adolescente a aplicar os conteúdos sistematizados a sua vida cotidiana, isso impediria que sua atividade se transformasse em uma fantasia improdutiva, alheia à vida, o que dificultaria a compreensão da própria vida.

Planejar mentalmente mudanças da realidade objetiva não é um processo simples, visto que o indivíduo necessita de conhecimento sobre a realidade na qual está inserido. Tal processo só é possível pela mediação das esferas de objetivações genéricas não cotidianas. Destarte, as condições concretas de vida podem se apresentar como fatores essenciais à criação de uma nova realidade, mas também podem se configurar como elementos impeditivos, o que obliteraria a imaginação do indivíduo, tal como ocorre na sociedade de classes, por exemplo.

\begin{abstract}
A desilusão, a integração da prosa da vida, a renúncia àquilo que na juventude se havia sonhado, que Ribot apresenta como lei geral da evolução da imaginação, não passa, na realidade, da "lei" do seu desenvolvimento, melhor, da sua perda sob o condicionamento da sociedade burguesa. A passagem à atividade prática no quadro da sociedade capitalista exige da juventude que entre na vida real, quando e sempre que pertença enquadrada nessa sociedade, que renuncie a tudo o que de melhor exista nos seus sonhos de juventude, que se submeta às tradições, à rotina, às normas estabelecidas e aos modelos e se ocupe de coisas prosaicas, onde não há lugar para a imaginação criadora. Nestas condições é natural que a imaginação vá diminuindo. (RUBINSTEIN, 1973, p. 123).
\end{abstract}

Não se pode falar em enriquecimento de possibilidades, de imaginação criativa, de desenvolvimento da personalidade, onde todas as necessidades e interesses humanos se reduzem ao em-si, ao meramente cotidiano e à lógica do capital. A luta por uma educação pública de qualidade, por uma educação escolar que socialize os conteúdos científicos, artísticos e filosóficos em suas formas mais desenvolvidas, tem como objetivo a inserção do adolescente nas esferas não cotidianas de objetivações genéricas e a possibilidade da formação de uma personalidade para-si, uma personalidade livre e universal. 
Podemos dizer que é precisamente em suas fantasias [imaginações] onde o adolescente vislumbra pela primeira vez seus planos de vida. Suas aspirações e confusos motivos se materializam em determinadas imagens. Na fantasia ele antecipa seu futuro e, por conseguinte, se aproxima com espírito criador a sua realização. (VYGOTSKI, 1996, p. 223).

Daí decorre, portanto, a necessidade do adolescente apropriar-se de conceitos científicos, frutos da educação escolar e indispensáveis à formação do pensamento abstrato e do desenvolvimento da imaginação criativa. Compreendemos que os conteúdos sistematizados, por si só, não transformam a realidade objetiva, mas é certo que, na ausência destes, seria impossível o desenvolvimento da imaginação em suas máximas possibilidades, impossível seria uma antecipação mental do produto da atividade, bem como uma transformação intencional da própria realidade objetiva.

\section{AGRADECIMENTOS: CAPES}

\section{REFERENCIAS}

DAVÍDOV, V. La enseñanza escolar y el desarrollo psíquico: investigación psicológica teórica y experimental. Moscu: Editorial Progreso, 1988.

DUARTE, N. Os conteúdos escolares e a ressurreição dos mortos: contribuição à teoria histórico-crítica do currículo. Campinas, SP: Autores Associados, 2016.

DUARTE, N. A individualidade para-si: contribuição a uma teoria histórico-social da formação do indivíduo. 3. ed. rev. Campinas, SP: Autores Associados, 2013.

IGNATIEV, E. I. La imaginación. In: SMIRNOV, A. A. et al. Psicologia. México: Grijalbo, p. 308-340, 1960.

KOPNIN, P. V. Logica dialectica. México: Editorial Grijalbo, S. A., 1966.

KOSIK, K. Dialética do concreto. 2. ed. Rio de Janeiro: Paz e Terra, 2011.

LEONTIEV, A. N. O desenvolvimento do psiquismo. Lisboa: Livros Horizonte, 1978.

MARTINS, L. M. O desenvolvimento do psiquismo e a educação escolar:

contribuições à luz da psicologia histórico-cultural e da pedagogia histórico-crítica.

Campinas, SP: Autores Associados, 2013.

MARX, K. Manuscritos econômico-filosóficos e outros textos escolhidos. São Paulo: Abril Cultural, 1978. (Coleção Os pensadores). 
MARX, K. Manuscritos econômico-filosóficos. São Paulo: Boitempo, 2015.

RUBINSTEIN, S. L. Princípios de psicologia geral. Lisboa: Editorial Estampa, 1973.

SACCOMANI, M. C. S. A criatividade na arte e na educação escolar: uma contribuição à pedagogia histórico-crítica à luz de Georgy Lukács e Lev Vigotski.

Campinas, SP: Autores Associados, 2016.

SAVIANI, D. Pedagogia Histórico-Crítica: primeiras aproximações. 11. ed.

Campinas: Autores Associados, 2011.

VIGOTSKI, L. S. Imaginação e criatividade na infância. São Paulo: Editora WMF Martins Fontes, 2014.

VIGOTSKI, L. S. Psicologia da arte. São Paulo: Martins Fontes, 1999.

VIGOTSKI, L. S. Obras escogidas. Tomo II. Madri: A. Machado Libros, S. A., 2001.

VYGOTSKI, L. S. Obras escogidas. Tomo IV. Madri: Visor, 1996.

\section{Como referenciar este artigo}

ANJOS, Ricardo Eleutério dos. O desenvolvimento histórico-cultural da imaginação na adolescência e a educação escolar. Temas em Educ. e Saúde, Araraquara, v.13, n.2, p. 271-285, jul./dez. 2017. Disponível em: <https://doi.org/10.26673/rtes.v13.n2.juldez.2017.9602>. E-ISSN: 2526-3471.

Submetido em: 25/03/2017

Aprovado em: 20/06/2017 